\title{
Exercise program improved subjective dry eye symptoms for office workers
}

This article was published in the following Dove Press journal:

Clinical Ophthalmology

\author{
Kokoro Sano' \\ Motoko Kawashima' \\ Sayuri Takechi ${ }^{2}$ \\ Masaru Mimura ${ }^{2}$ \\ Kazuo Tsubota' \\ 'Department of Ophthalmology, \\ ${ }^{2}$ Department of Neuropsychiatry, \\ Keio University School of Medicine, \\ Tokyo, Japan
}

Introduction: We investigated the benefits of a cognitive behavior therapy-based exercise program to reduce the dry eye symptoms of office workers.

Materials and methods: We recruited 11 office workers with dry eye symptoms, aged 31-64 years, who voluntarily participated in group health guidance at a manufacturing company. Participants learned about the role of physical activity and exercise in enhancing wellness and performed an exercise program at home 3 days per week for 10 weeks. We estimated the indexes of body composition, dry eye symptoms, and psychological distress using the Dry Eye-Related Quality of Life Score and the World Health Organization's Subjective Well-Being Inventory questionnaires pre- and postintervention.

Results: The 10-week exercise program and the questionnaires were completed by $48.1 \%$ (39 of 81) of the participants. Body composition did not change pre- and postintervention. However, the average of the Dry Eye-Related Quality of Life Score scores in participants with subjective dry eye significantly improved after the intervention. Moreover, the World Health Organization's Subjective Well-Being Inventory positive well-being score tended to increase after the intervention.

Conclusion: In this study, we showed that a 10-week exercise program improved subjective dry eye symptoms of healthy office workers. Our study suggests that a cognitive behavior therapy-based exercise program can play an important role in the treatment of patients with dry eye disease.

Keywords: dry eye, exercise, office workers, cognitive behavioral therapy

\section{Introduction}

Due to the recent increase in the use of technology in office workplaces, dry eye disease (DED) has become an important health problem among office workers in Japan. ${ }^{1}$ DED causes discomfort, visual disturbance, and tear film instability. ${ }^{2-4}$ Moreover, it is possible that DED leads to deterioration in office work performance. ${ }^{5}$ Therefore, DED should be involved in the health management of office workers. There are many reasons for the increase in DED patients. The widespread use of visual display terminals (VDTs) is one of these reasons. Office workers usually use VDT for long workdays. This VDT work style brings a lack of physical activity as well as DED symptoms due to viewing a computer screen for long periods of time. In fact, it has been reported that VDT use is a strong risk factor for DED. ${ }^{6}$ Furthermore, a recent study has reported that lower physical levels and sedentary behavior were associated with DED. ${ }^{7}$ However, few studies have discussed the association between DED and lifestyle, especially exercise habits, in office workers.

More recently, some studies have investigated the association between DED and depression. ${ }^{8-10}$ It has also been reported that depression is related to obesity and
Correspondence: Motoko Kawashima Department of Ophthalmology, Keio University School of Medicine, 35 Shinanomachi, Shinjuku-ku,

Tokyo 160-8582, Japan

Tel +8I 353633866

Fax +8I 353633045

Email motoko-k@a3.keio.jp
Clinical Ophthalmology 2018:12 307-31।

307 
metabolic disorders that develop due to lower physical activity levels. ${ }^{11,12}$ It is possible that the onset of DED and depression is related to exercise habits. We hypothesize that DED and depression may have the same background: decrease of exercise time. Therefore, we focus on a cognitive behavioral therapy (CBT)-based exercise program for DED prevention. CBT has been confirmed to be effective for the treatment of depression and has recently been used to treat patients with various conditions other than mental illness. CBT has been used to treat patients with various conditions; for example, chronic pain and poor diet. ${ }^{13,14}$ Moreover, it has been reported that a CBT-based exercise program reduces psychological distress among employees. ${ }^{15}$

The purpose of this study was to investigate the association between dry eye symptoms and a CBT-based exercise program. We evaluated the potential benefits of a 10 -week home exercise program for reducing dry eye symptoms among office workers.

\section{Materials and methods}

\section{Participants}

We recruited office workers at a manufacturing company who voluntarily participated in group health guidance. Between November 2013 and February 2014, we enrolled 11 office workers with subjective dry eye symptoms who worked in the three offices of a general business company. The average of the participants' daily work time was $\sim 8$ hours. Participants in this study were aged 31-64 years. They had no serious disease or significant medical history and agreed to participate in this study, which included an exercise program. Written informed consent was obtained from all participants. We excluded individuals who were unable to give written consent and those who were unable to exercise due to conditions such as heart disease, cerebrovascular disease, or orthopedic disease. The research protocol was approved by the Ethics Committee of the Keio University School of Medicine.

\section{Interventions}

We made use of a CBT-based exercise program. First, participants were educated about the way exercise can regulate health and prevent disease. Participants were also educated about the role of physical activity and exercise behavior in enhancing wellness. Next, a psychologist explained dysfunctional thinking or behavior that could prevent engaging in exercise. Furthermore, a health exercise instructor gave participants practical guidance on a specific exercise program. Participants engaged in a 10 -week exercise program at home following a CBT-based exercise program workbook.

\section{Confirmation of the practical guidance} on a specific exercise program

- A health exercise instructor gave participants practical guidance on a specific exercise program.

- Participants measured body composition. (preintervention)

- Participants answered Schaumberg questionnaire.

- Participants answered DEQS. (preintervention)

- Participants answered WHO SUBI. (preintervention)

10-week exercise program

- Participants engaged in 10-week exercise program at home following the workbook.

- Exercise consisted of a warm-up period, five types of core strength training, and a cool-down period.

- Exercise was recommended as 3 days per week.

Measurement body composition

- Participants measured body composition. (postintervention) - Participants answered DEQS. (postintervention)

- Participants answered WHO SUBI. (postintervention)

Figure I Protocol in this study.

Abbreviations: DEQS, Dry Eye-Related Quality of Life Score; WHO SUBI, World Health Organization's Subjective Well-Being Inventory.

Exercises consisted of a warm-up period, five types of core strength training (squats, lunges, sit-ups, crunches, and arm and leg raises), and a cool-down period. Patients were advised to perform the exercises 3 days per week (Figure 1).

\section{Evaluations}

We gave group guidance to the participants at the beginning of the program as preintervention and at the closing of the program postintervention 10 weeks after the beginning.

We measured the participants' indexes of body composition, weight, body fat, and abdominal circumference using Inbody 470 (Inbody Japan Inc., Tokyo, Japan). We used the Women's Health Study Questionnaire (Schaumberg questionnaire). This included three questions pertaining to diagnosis or symptoms of DED: 1) Have you ever been diagnosed by a clinician as having dry eye syndrome? 2) How often do your eyes feel dry (not wet enough)? 3) How often do your eyes feel irritated? Participants answered (2) and (3) with any of the following: "constantly," "often," "sometimes," or "never." This questionnaire was validated against standardized clinical practice. ${ }^{16,17}$

Moreover, we used the Japanese dry eye symptom questionnaire, Dry Eye-Related Quality of Life Score (DEQS). ${ }^{18}$ The DEQS correlated well with eight mental components and showed strong correlations with four subscales. Response choices for each question about the symptoms were "constantly," "often," "sometimes," and "never." Each subjective symptom was given a score of 1 if the symptom rating was "constantly" or "often." The DEQS 
questionnaire was valid and reliable for evaluating the multifaceted effect of DED on the patient's daily quality of life, including mental health, in clinical practice.

Additionally, we evaluated psychological distress using the World Health Organization's Subjective Well-Being Inventory (WHO SUBI). The WHO SUBI was developed to measure subjective well-being and positive and negative feelings. It consisted of 40 questions and answers that were given on a 3 -point scale. ${ }^{19,20}$

\section{Statistical analysis}

Statistical analyses were performed using a commercially available software package, Excel Toukei (SSRI, Tokyo, Japan). A two-tailed Student's $t$-test was used for all analyses. Statistical significance was established at $P<0.05$.

\section{Results}

All participants completed the questionnaires and 10-week exercise program (Figure 1). The characteristics of participants and the results of the Schaumberg questionnaire are shown in Table 1. Body composition did not change between pre- and postintervention (Table 2). The average DEQS scores in participants with subjective dry eye symptoms significantly decreased (pre: $40.8 \pm 16.3$, post: $27.0 \pm 10.1$, $P=0.03$, Student's $t$-test) after the intervention (Figure 2).

The WHO SUBI-positive well-being score and the WHO SUBI-negative well-being score did not change between pre- and postintervention (SUBI-positive well-being score: pre $35.1 \pm 13.1$, post $38.6 \pm 6.8$, SUBI-negative well-being score: pre 43.1 \pm 15.7 , post $46.6 \pm 8.6$ ) (Figure 3).

\section{Discussion}

DED symptoms improved using an exercise intervention in this study. This finding supports the hypothesis regarding an association between DED and exercise habits, and mechanisms regarding how exercise reduces dry eye symptoms should be elucidated in a future study. We have reported that a lower level of physical activity and sedentary behavior are associated with DED in humans ${ }^{7}$ and doing exercise led to tear secretion in mice. ${ }^{21}$ Based on those results and those of the present study, we suppose that exercise habits have

Table I Characteristics of participants

\begin{tabular}{ll}
\hline Characteristic & Subjective dry eye symptoms $(\mathbf{n}=\mathbf{I} \mathbf{I})$ \\
\hline Age, mean \pm SD (range) & $48.5 \pm$ I I.0 (3I-64) \\
Sex, no (\%) & \\
$\quad$ Male & $6(54.5)$ \\
Female & $5(45.5)$ \\
\hline
\end{tabular}

Table 2 Body composition of participants

\begin{tabular}{|c|c|c|c|c|}
\hline $\begin{array}{l}\text { Body } \\
\text { composition }\end{array}$ & $\mathbf{n}$ & Preintervention & Postintervention & $P$-value \\
\hline Body weight (kg) & 10 & $63.5 \pm 12.1$ & $63.7 \pm 12.0$ & 0.97 \\
\hline $\begin{array}{l}\text { Skeletal muscle } \\
\text { mass }(\mathrm{kg})\end{array}$ & 10 & $31.1 \pm 12.1$ & $25.7 \pm 5.8$ & 0.22 \\
\hline $\begin{array}{l}\text { Amount of body } \\
\text { fat }(\mathrm{kg})\end{array}$ & 10 & $16.4 \pm 6.2$ & $17.5 \pm 6.9$ & 0.98 \\
\hline $\begin{array}{l}\text { Fuselage muscle } \\
\text { mass }(\mathrm{kg})\end{array}$ & 9 & $19.8 \pm 4.0$ & $19.8 \pm 3.8$ & 0.99 \\
\hline $\begin{array}{l}\text { Amount of } \\
\text { fuselage fat }(\mathrm{kg})\end{array}$ & 9 & $7.9 \pm 2.4$ & $7.8 \pm 2.8$ & 0.92 \\
\hline $\begin{array}{l}\text { Circumference of } \\
\text { waist }(\mathrm{cm})\end{array}$ & 8 & $77.5 \pm 6.9$ & $77.8 \pm 6.6$ & 0.91 \\
\hline Visceral fat level & 8 & $7.6 \pm 1.5$ & $6.3 \pm 1.5$ & 0.11 \\
\hline
\end{tabular}

a positive effect for the prevention of DED. Decrease of metabolism after sedentary behavior and a lower level of physical activity may be associated with tear secretion. If this hypothesis is true, we can explain why DED increased due to the spread of VDT work. Increase of sedentary behavior due to VDT work may lead to metabolic change, and tear secretion may decrease accordingly.

In our study, the WHO SUBI positive well-being score tended to increase but showed no significance. We have reported the association between subjective happiness and DED. The subjective happiness scale score was inversely correlated with the DED symptoms score in one study. ${ }^{21,22}$ DED symptoms are possibly associated with subjective happiness and positive well-being. In another study, the subjective happiness scale of the depression group was lower than that of the healthy group..$^{22,23}$ Subjective happiness and positive well-being factors may affect both DED and depression.

This study had some limitations that might affect our interpretation of our results. We only implemented the

\begin{tabular}{lllll}
\hline DEQS & $\mathbf{n}$ & Preintervention & Postintervention & $\boldsymbol{P}$-value \\
\hline $\begin{array}{l}\text { Subjective dry } \\
\text { eye symptoms }\end{array}$ & 11 & $40.8 \pm 16.3$ & $27.0 \pm 10.1$ & 0.03 \\
\hline
\end{tabular}

Subjective dry eye symptoms

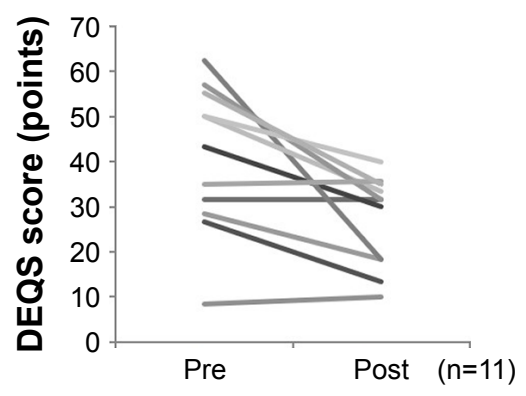

Figure 2 The change of DEQS scores in participants. Abbreviation: DEQS, Dry Eye-Related Quality of Life Score. 


\begin{tabular}{lllll}
\hline WHO SUBI & $\mathbf{n}$ & Preintervention & Postinternvention & $\boldsymbol{P}$-value \\
\hline Positive well-being & 11 & $35.1 \pm 13.1$ & $38.6 \pm 6.8$ & 0.45 \\
Negative well-being & 11 & $43.1 \pm 15.7$ & $46.6 \pm 8.6$ & 0.52 \\
\hline
\end{tabular}
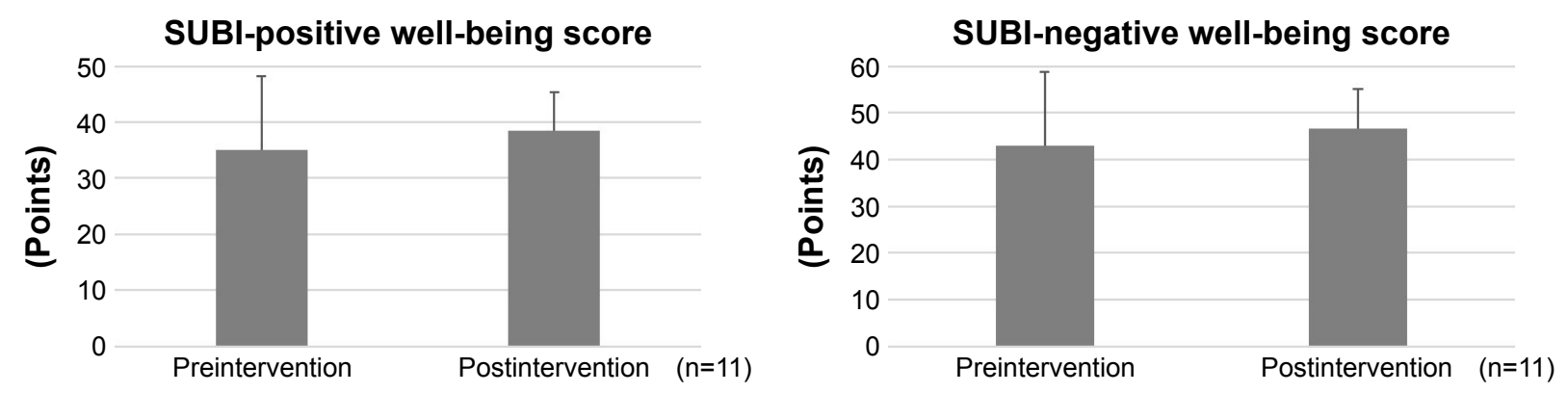

Figure $3 \mathrm{WHO}$ SUBI scores in participants.

Note: Each column shows the mean \pm SD .

Abbreviation: WHO SUBI, World Health Organization's Subjective Well-Being Inventory.

questionnaires to estimate the participants' subjective opinion of DED symptoms. We did not examine objective signs. Prospective studies to examine a combination of objective and subjective symptoms are needed to understand the mechanisms underlying the association between exercise habits and DED. Another limitation of our study is that we only studied the questionnaires of 11 people during a very short time span. Further interventional studies are necessary to improve our understanding of the effect of exercise on DED symptoms in larger study groups and longer periods of time. And we should also consider selection bias in this study.

\section{Conclusion}

In conclusion, the results of the present study showed that a 10 -week exercise program improved the subjective symptoms of DED in office workers. Our study suggests that a CBT-based exercise program can play an important role in the treatment of patients with DED.

\section{Disclosure}

The authors report no conflicts of interest in this work.

\section{References}

1. Uchino M, Uchino Y, Dogru M, et al. Dry eye disease and work productivity loss in visual display users: the Osaka study. Am J Ophthalmol. 2014;157(2):294-300.

2. Goto E, Yagi Y, Matsumoto Y, Tsubota K. Impaired functional visual acuity of dry eye patients. Am J Ophthalmol. 2002;133(2):181-186.

3. Nelson JD, Helms H, Fiscella R, Southwell Y, Hirsch JD. A new look at dry eye disease and its treatment. Adv Ther. 2000;17(2):84-93.

4. The definition and classification of dry eye disease: report of the Definition and Classification Subcommittee of the Interventional Dry Eye Workshop. Ocul Surf. 2007;5(2):75-92.

5. Yamada M, Mizuno Y, Shigeyasu C. Impact of dry eye on work productivity. Clinicoecon Outcomes Res. 2012;4(1):307-312.
6. Uchino M, Yokoi N, Uchino Y, et al. Prevalence of dry eye disease and its risk factors in visual display terminal users: the Osaka study. Am J Ophthalmol. 2013;156(4):759-766.

7. Kawashima M, Uchino M, Yokoi N, et al. The association between dry eye disease and physical activity as well as sedentary behavior: results from the Osaka study. J Ophthalmol. 2014;2014:943786.

8. Hallak JA, Tibrewal S, Jain S. Depressive symptoms in patients with dry eye disease: a case-control study using the beck depression inventory. Cornea. 2015;34(12):1545-1550.

9. van der Vaart R, Weaver MA, Lefebvre C, Davis RM. The association between dry eye disease and depression and anxiety in a large population-based study. Am J Ophthalmol. 2015;159(3):470-474.

10. Na KS, Han K, Park YG, Na C, Joo CK. Depression, stress, quality of life, and dry eye disease in Korean women: a population-based study. Cornea. 2015;34(7):733-738.

11. Morikawa M, Okamaoto N, Kiuchi K, et al. Association between depressive symptoms and metabolic syndrome in Japanese communitydwelling older people: a cross-sectional analysis from the baseline results of the Fujisawa-kyo prospective cohort study. Int $J$ Geriatr Pshychiatry. 2013;28:1251-1259.

12. De WL, Luppino F, Van SA, et al. Depression and obesity: a meta-analysis of community-based studies. Psychiatry Res. 2010;178:230-235.

13. Ehde DM, Dillworht TM, Turner JA. Cognitive-behavioral therapy for individuals with chronic pain: efficacy, innovations, and directions for research. Am Psychol. 2014;69(2):153-166.

14. Tsiros MD, Sinn N, Brennan L, et al. Cognitive behavioral therapy improves diet and body composition in overweight and obese adolescents. Am J Clin Nutr. 2008;87:1134-1140.

15. Takechi S, Kikuchi T, Horisawa S, et al. Effectiveness of a cognitive behavioral therapy-based exercise program for healthy employees. Adv Physical Educ. 2015;5:263-272.

16. Schaumberg DA, Sullivan DA, Buring JE, et al. Prevalence of dry eye syndrome among US women. Am J Ophthalmol. 2003;136(2):318-326.

17. 2007 Report of the international dry eye workshop (DEWS). Ocul Surf. 2007;5(2):100-105.

18. Sakane Y, Yamaguchi M, Yokoi N, et al. Development and validation of the dry eye-related quality-of-life score questionnaire. JAMA Ophthalmol. 2013;131(10):1331-1338.

19. Fujinami K, Sonoda A, Ono Y. Preparation of Japanese version of SUBI and examination of reliability. Japanese J Health Psychol. 1996;8: 12-19. Japanese.

20. Ono Y, Yoshimura K. Japanese Version of WHO SUBI. Kaneko shobo, 2014. 
21. Sano K, Kawashima M, Ito A, et al. Aerobic exercise increases tear secretion in type 2 diabetic mice. Invest Ophthalmol Vis Sci. 2014;55(7) 4287-4294.

22. Kawashima M, Uchino M, Yokoi N, et al. Associations between subjective happiness and dry eye disease: a new perspective from the Osaka study. PLoS One. 2015;10(4):e0123299.
23. Shimai S, Otake K, Utsuki N, et al. Development of a Japanese version of the subjective happiness scale (SHS), and examination of its validity and reliability. Nihon Koshu Eisei Zasshi. 2004;51(10):845-853. Japanese.

\section{Publish your work in this journal}

Clinical Ophthalmology is an international, peer-reviewed journal covering all subspecialties within ophthalmology. Key topics include: Optometry; Visual science; Pharmacology and drug therapy in eye diseases; Basic Sciences; Primary and Secondary eye care; Patien Safety and Quality of Care Improvements. This journal is indexed on

Submit your manuscript here: http://www.dovepress.com/clinical-ophthalmology-journal

\section{Dovepress}

PubMed Central and CAS, and is the official journal of The Society of Clinical Ophthalmology (SCO). The manuscript management system is completely online and includes a very quick and fair peer-review system, which is all easy to use. Visit http://www.dovepress.com/ testimonials.php to read real quotes from published authors. 